\title{
LANDFILL URBANISM: OPPORTUNISTIC ECOLOGIES, WASTED LANDSCAPES
}

\section{Dan Weissman *}

Lam Partners, 84 Sherman Street Cambridge MA 02140, United States

Article Info:
Received:
12 Februray 2020
Revised:
5 May 2020
Accepted:
20 May 2020
Available online:
23 July 2020
Keywords:
Landfill
Waste
Flows
Energy
Capital
Infrastructure

\section{INTRODUCTION}

Hills rise in the dross of the American post-industrial landscape. Surrounded by nondescript warehouses, oceans of asphalt and retention ponds, expansive PTFE bowls are filled, covered, capped and monitored. Typically situated at the perimeter of the urban landscape, landfills have, in recent years become consumed by the confines of civilization. Yet the increased demand for material coupled with decreased natural availability, as well as heightened policy measures barring landfill site development and airspace, have collectively fostered a growing crisis of waste management. Blane Brownell exclaims in his essay Material Ecologies in Architecture, "Citing a recent USGS study, American Environmentalist Lester Brown informs us that we will exhaust known stores of several metals, including lead, copper, iron ore, and aluminum, vital to construction and other industries, within the next two or three generations." The extraction of existing land- fill sites for material, energy and airspace is thus inevitable (Figure 1).

Landfill Urbanism proposes logistics, operations and architectures requisite of landfill extraction as a catalyst to implement a multifarious agenda aimed at fostering localized industrial, commercial and recreational ecologies across its industrial zone (as well as novel operations within the confines of the site). Positioned in the reality of our current economic and political environment, the project envisions a deterministic future encompassing technological advancement pitted against increased environmental degradation, and an urgency for alternatives (or augmentations) to existing societal practices. No more merely the mummified mass, the landscape of the landfill fulfills its destiny as an agent continuously manipulated by the wills of civilization, throbbing to the pulse of the urban metabolism, while also working as a catalyst to foster a thickened, yet localized industrial ecology (Figure 2). 

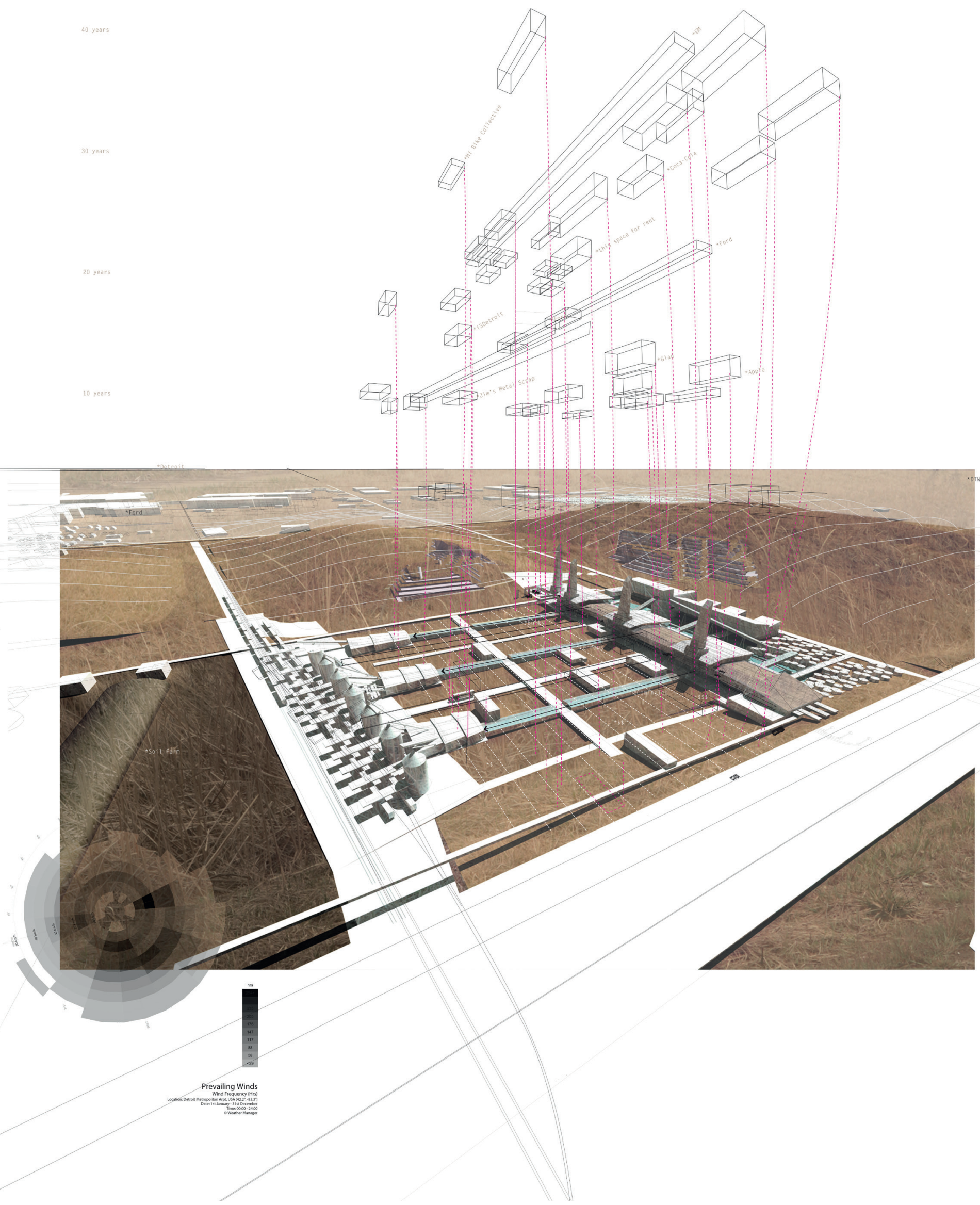

FIGURE 1: The infrastructure of emergent sorting. 


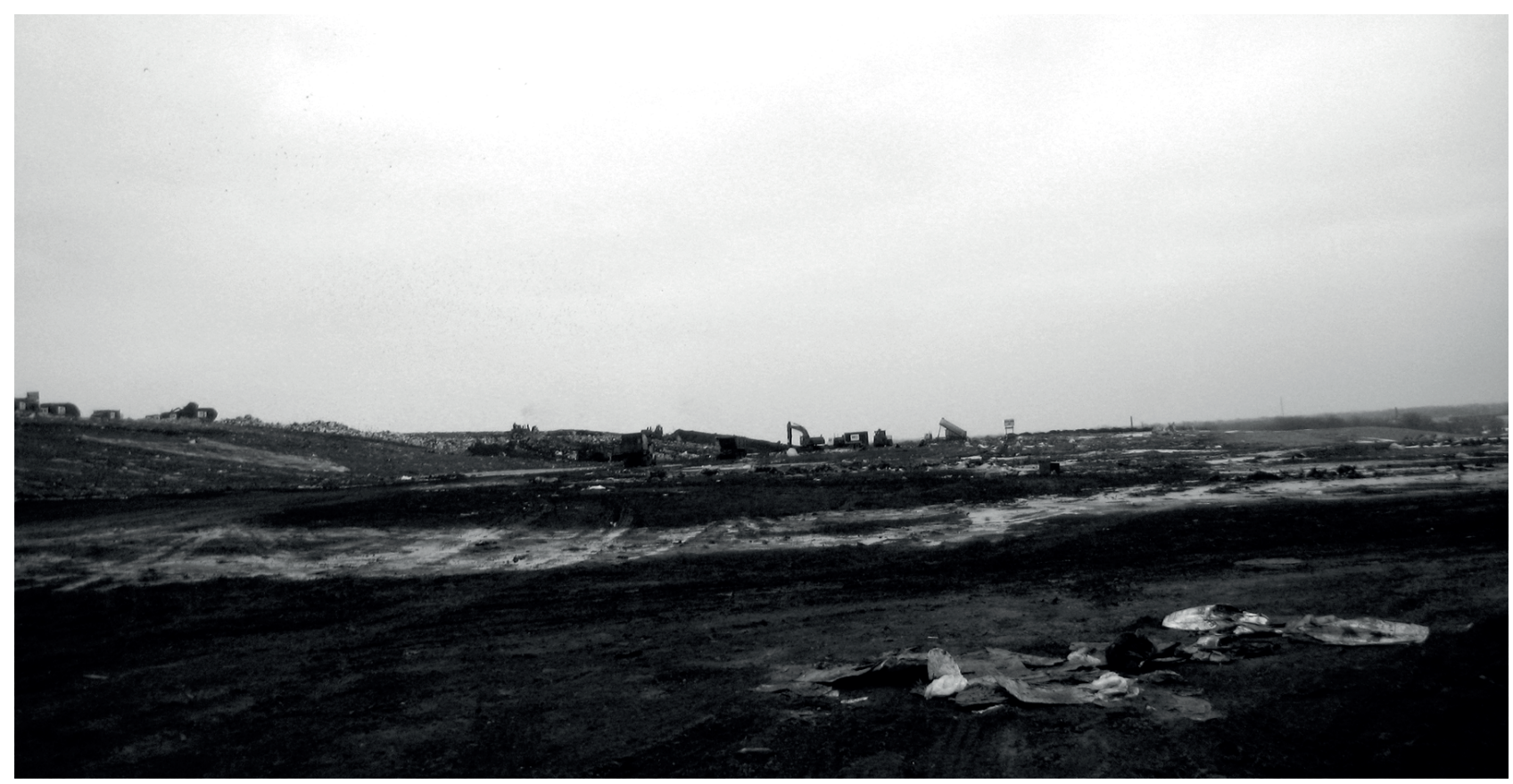

FIGURE 2: The mound.

This paper summarizes a Master Thesis published in 2010, at the University of Michigan Taubman College of Architecture. Nevertheless, the proposed project may continue to be of interest to professionals and academics working in the field of Waste Architecture.

\section{LANDSCAPES OF OBSOLESCENCE}

Alan Berger connotes wasted land as Drosscape, illustrating in his text a categorical set of distinct dross territories visible throughout North America. Of these territories, the Landscapes of Obsolescence (LOO's) render visible the open loop in material and energy flows. The Landfill, out of the public consciousness, is neglected. Due to the lack of strong governmental oversight, Landfill operations have historically been a breeding ground for corruption, excess, and sluggish-to-backward environmental stewardship, its owners focused on waste quantity as income. Recent shifts, due to a more enlightened public, and stringent policy decisions following 1990's 'Subtitle D' Federal mandates, have served to increase awareness of the waste management process. Or at least increase the marketing campaigns by the largest waste management corporations expounding their environmental stewardship.

Regardless, the generation of waste is clear. We Americans produce on average some $2 \mathrm{Kg}$ (4.39 lbs) of waste per day. However, for much of human history, waste collection and disposal were a purely local process dealing primarily with organic matter, generally relying on natural processes to ultimately renew waste into usable material. The proliferation of inorganic materials into the $20-21$ st century waste stream has exacerbated traditional waste handling procedures of in-ground disposal or incineration. While costs incurred extracting virgin resources continue to mount, re- cycling programs have yet to make a significant impact on waste reduction.

\section{GLOBAL LOGISTICS NETWORKS. FORM FOLLOWS ENERGY}

The landfill is, by all accounts, the end node of global flows of capital, save for the burgeoning market for landfill gas extraction, and the transfer of capital into the pockets of corporate waste management and government entities (which does not account for the potential worth of material dumped). It is where investment goes to die. In this role as end node, the landfill gives physical form to the inefficiencies in our systems of civilization: it grows, mocking us and our inability to keep such material (and therefore energy or capital) flowing. But why let that be? The material is not gone; as the first law of thermodynamics states, energy within a system is neither created nor destroyed. The landfill is not the end of the system, even though it seems that way given today's practices. What if the landfill is merely a bottleneck inhibiting flow? Landfill extraction removes the bottleneck, injecting currently secluded material back into circulation (Figure 3 ).

The nascent potential of landfill extraction may, when endeavored upon, tap right back into the markets and flows by which it came. The mechanisms in our society that allow Walmart, McDonalds, or Amazon to deliver products have conditioned us to assume their methods of material transfer are the only solution. Landfill mining, when linked into global supply lines, could, and by many accounts should, bypass the local scale. However, as Pierre Belanger notes in his essay Landscape as Infrastructure, a shift is occurring "from conventionally large, centralized industries of mass production to a decentralized pattern of production."

Global networks require a coarse level of granularity to maintain efficiency, such as seen in standard recycling 


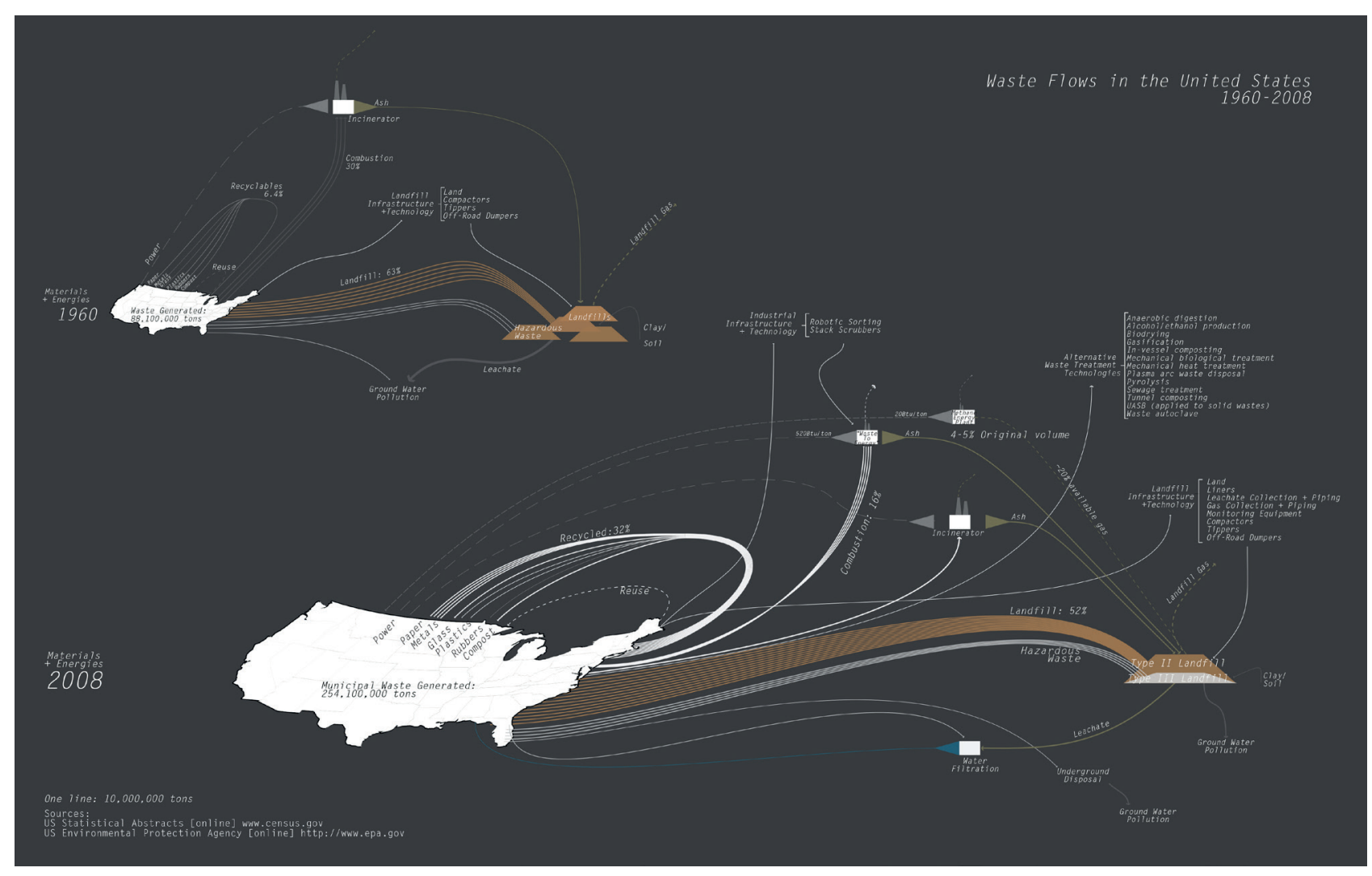

FIGURE 3: Material flows.

facilities that sort material by major commodities. This method of sorting does not account for any non-standard or finer grained elements in the system, and therefore sees anything unprofitable as waste. Landfill Urbanism offers an alternative: do both. Engage global networks while also offering direct public access unmediated by such networks, allowing for fine-grained economies to fill the gap. Foster emergent localized networks to provide that last percentage of efficiency unavailable to global flows. In plain terms: send out the bulk plastics and metals, but only after they've been sifted through by individuals who may find more immediate use for the oddities exhumed from the fill. Although not guaranteed, this may facilitate interdependent industrial networks at multiple scales similar to existing landfill networks, projecting completely unforeseen growth patterns (Figure 4).

As Peter Hasdall, in his essay Pneuma: An Indeterminate Architecture, or Toward a Soft and Weedy Architecture, explains that "A possible framework for reconceptualizing the design of ecologies as a raw, open-ended, open-sourced and non-prescriptive research-based practice is outlined ... as Pneuma. As a point of departure, this practice comprehends architecture as a mediating entity (a medium) that regulates flows and balances in an ecological field." Therefore, although grounded in the requisite industrial operations, Landfill Urbanism's architecture becomes an active agent, heightening operations beyond industrial infrastructure to project new and emergent relationships between material and energy flows, local climate, infrastructure and humans.

\section{EXPLORING THE SORTED PROJECT}

As of 2010, the State of Michigan was the third largest importer of waste in the United States, and in 2009, twenty percent of the material landfilled in the state originated in the Toronto region of Ontario, Canada. To address this alarming statistic, the newly formed Federal Agency for Waste Reclamation, or FAWR, seeds funds to the State of Michigan to develop a pilot program. Michigan's Department of Natural Resources and Environment, the agency responsible for landfill development, management and oversight, partners with the Department of Energy, Labor and Economic Growth to form the Southeast Michigan Landfill Development Initiative (SEMLDI). Charged with developing programs to productively utilize the state's growing resources found within landfills, the Woodland Meadows Landfill constellation has been chosen for this historic pilot project (Figure 5).

Twenty miles from Detroit near the Industrial community of Wayne, Waste Management Inc. owns and operates the $80+$ ha $(200+$ acre) active Woodland Meadows landfill adjacent to two capped landfills. This campus of waste resides adjacent to an additional $80+$ ha (200+acre) landfill operated by Republic Waste Services across Interstate 275. These two active fills represent almost a third of the airspace available in the southeast Michigan Region (Figure 6).

The Sorted Project is the primary sorting facility on site. Just as sorting adds value to material, so to can architecture become that 'value added' to a large territorial project. Stan Allen, in his essay Infrastructural Urbanism 


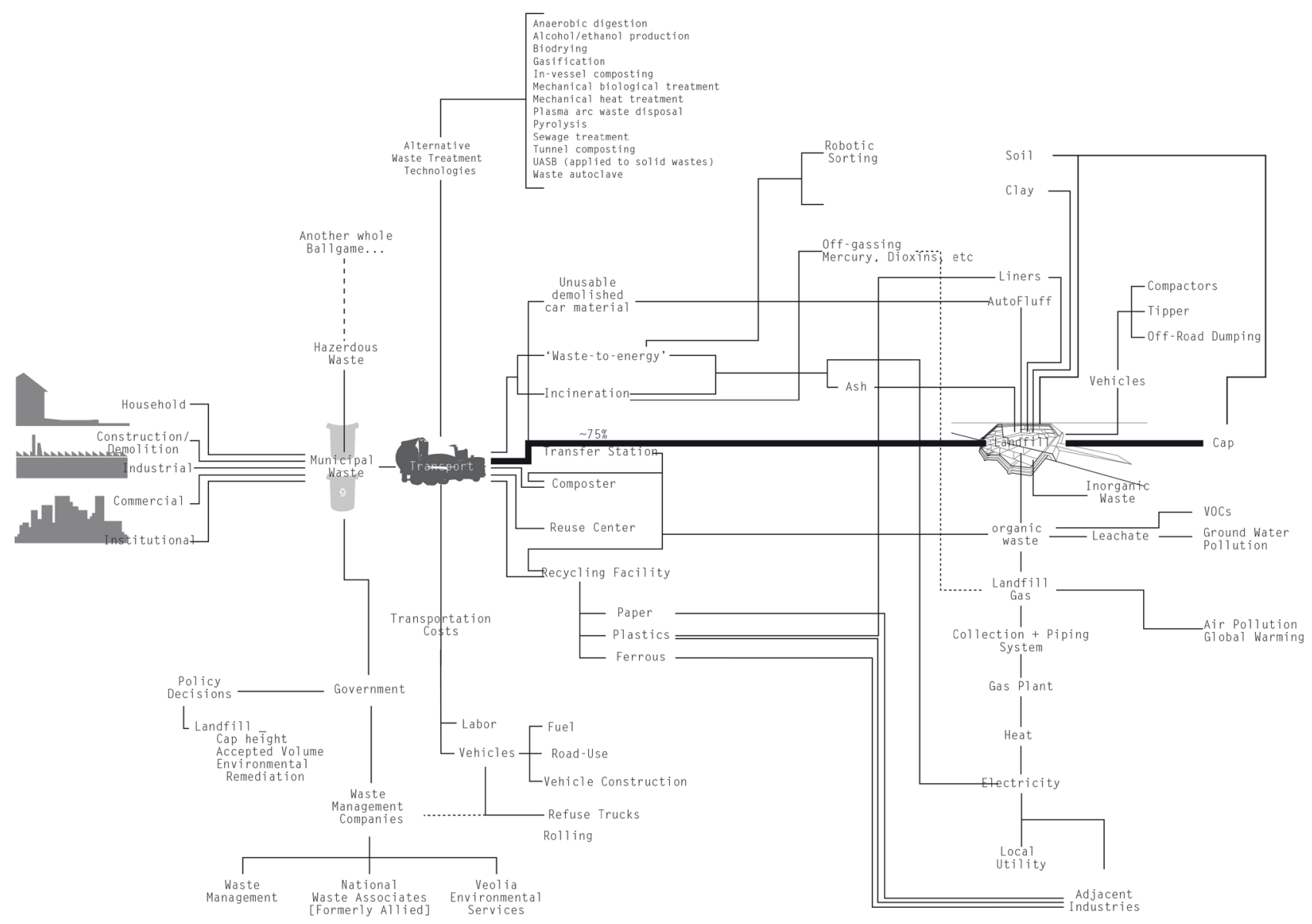

FIGURE 4: Taxonomies.

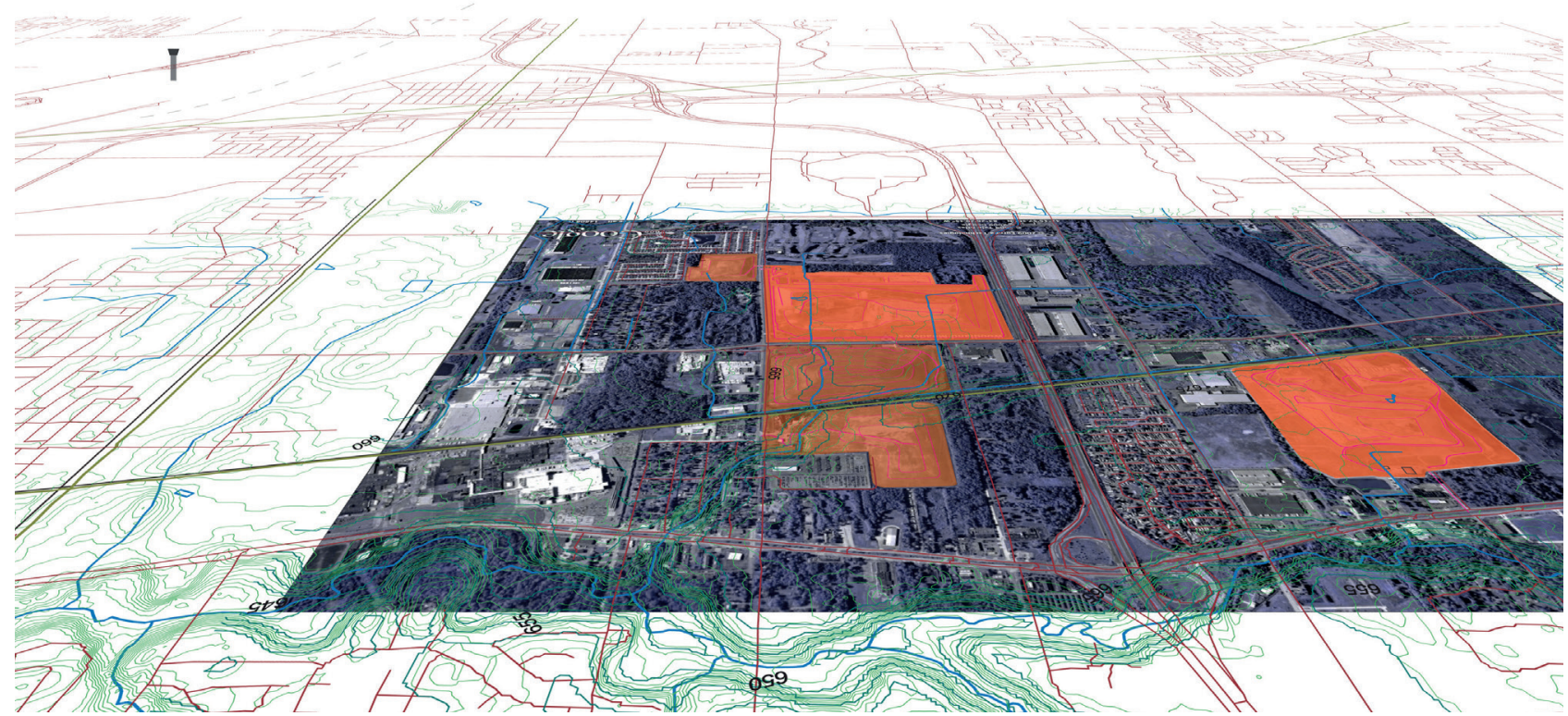

FIGURE 5: Site perspective. 


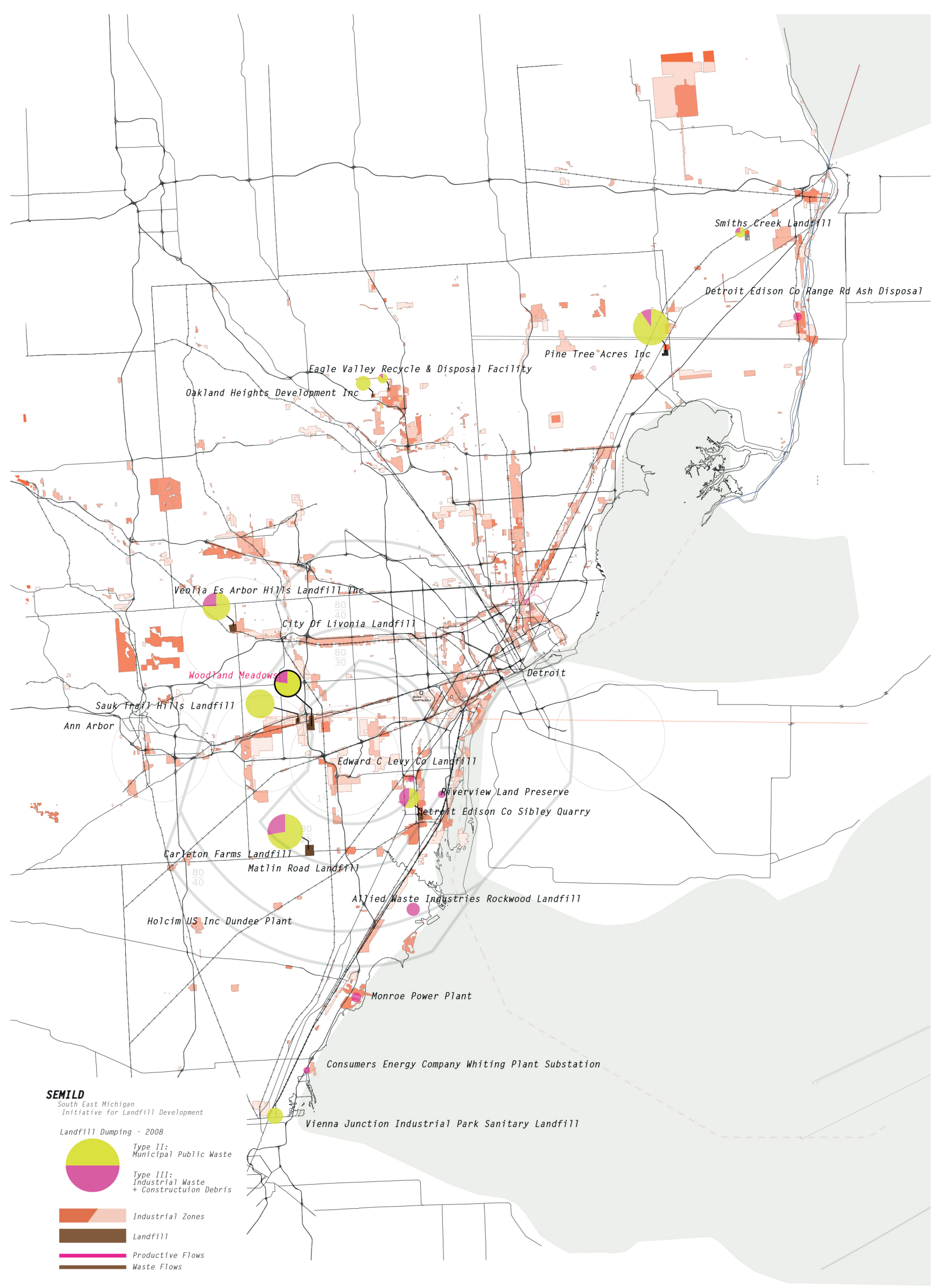

FIGURE 6: Detroit regional landfills, 2008. 
notes that "Architecture is uniquely capable of structuring the city in ways not available to practices such as literature, film, politics, installation art, or advertising. Yet because of its capacity to actualize social and cultural concepts it can also contribute something that strictly technical disciplines such as engineering cannot." Where typical industrial facilities hide themselves from the public, here the architecture seeks to say: "Come explore me!".

Site for the work exists in multiple arenas across the landscape. First, situated on the landfill, extraction machines creep across the mounds, exhuming entombed material, ATVs skirting around DRTEs. After initial extraction, material is trucked to adjacent facilities, sorted into basic material categories where applicable: Metals, plastics, paper products, organic material. Waste material, typically categorized and sorted by these elemental substances, takes on new agency, as the taxonomy of material becomes a critical player in the spatialization of operations with possibility for emergent conditions of alternative sorting. The architecture of the sorting facility naturally evolves a series of networks, housing space specifically targeted as an incubator for entrepreneurial interaction that may capitalize on these non-traditional taxonomies. The obsessive compulsive will cull every measuring device exhumed, while the 'Glad' company contracts to capture all spent plastic bag material; the Geek Squad collects all E-waste, or an artist will rent space as a testing ground for multi-media work. In this alternative sorting, rusty rebar, Styrofoam cups and electric scissors are all implicated.

Any matter unable to be reused is either partitioned as hazardous waste or sent to the power plant for incineration. Water is processed through a series of bioremediation drops before returning to the retention pond for use as coolant and cleaning water for both the sorting and power generation facilities. The power plant will intensify power generation capabilities of the landfill by incorporating landfill gas processing, waste-to-energy processing, and various other technologies, including leachate geo-thermal, wind and other available renewables. Fly ash created as waste from the incinerator is sent to a concrete manufacturer nearby for use as aggregate (Figures 7).

Seen through the lens of the long view snapshot, the Woodland Meadows site is tracked from inception through multiple states of dumping, excavation and use. Politics and economics govern project feasibility; as sorting production fluctuates, facilities grow and shrink to accommodate demand. As the mounds evolve, so too does the architecture. Build-up of sorted material occurring on site renders legible the status of material use and waste in the region. As extraction architecture remolds the landscape,

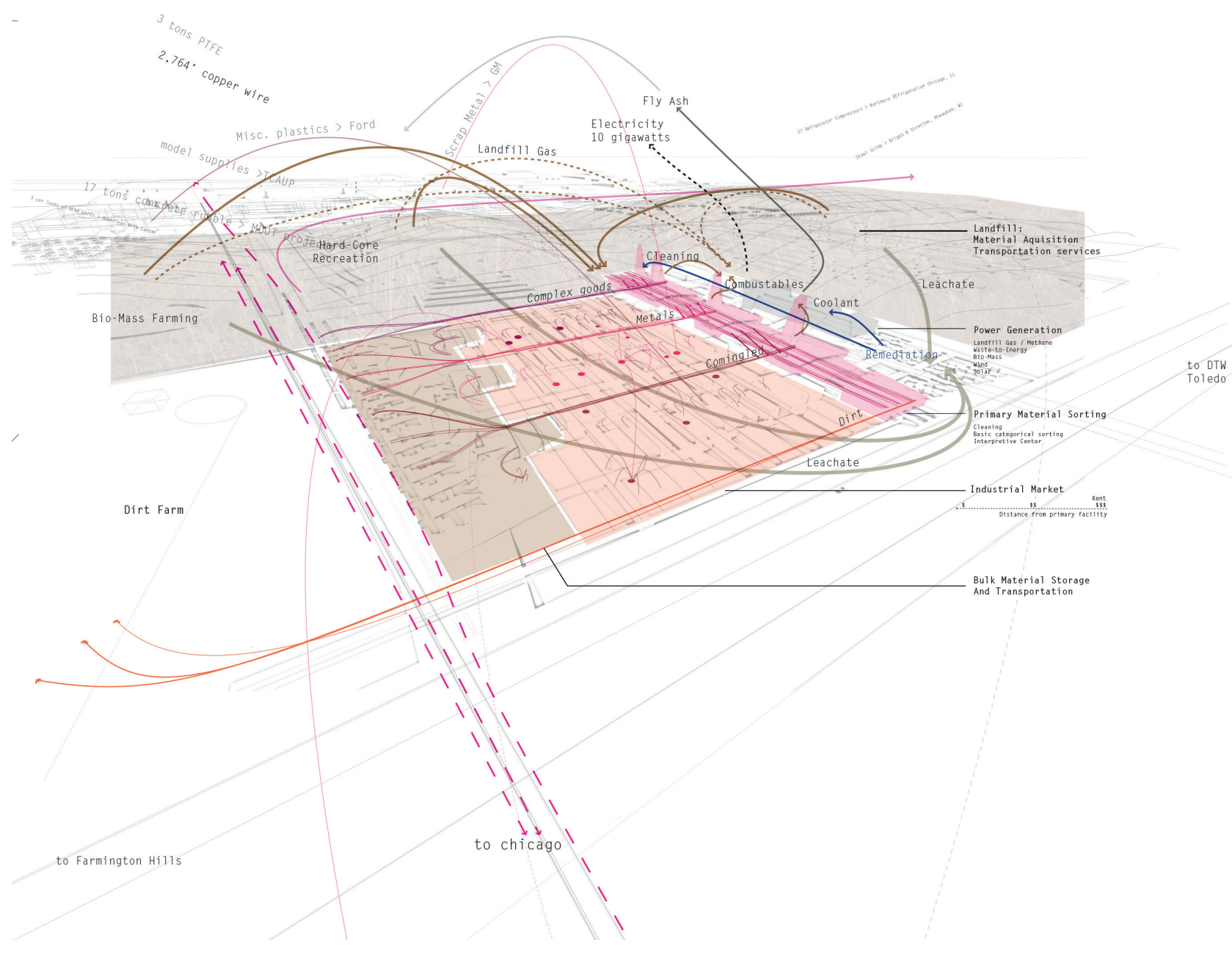

FIGURE 7: Site flows. 
off-road sport takes advantage of this continuously repackaged condition, gloriously conquering the territory.

\subsection{On the fill}

Directed Robotic Trash Extractors, or DRTEs, and other mining equipment extract material, as recreational activities such as ATVs or mountain bike riding, snowmobile or even DRTE rides take advantage of the constantly remolded landscape (Figures 8, 9).

\subsection{The power station}

Directly adjacent to the mound, this facility harnesses energy from multiple sources: landfill gas, methane, waste material and biomass incineration, distributing the energy across the project, as well as supplying local businesses such as the Ford assembly plant down the road (Figure 10).

\subsection{The Remediation pond}

Handling runoff and leachate from the surrounding landfills, the remediation pond serves to clean and recycle water from both the sorting facility, and power station for reuse as cleaning and coolant in both facilities. A living machine filters out heavy metals and other toxins.

\subsection{The Headhouse}

Three Head-houses serve as transition points from primary sorting to the line conveyor belts, carrying material

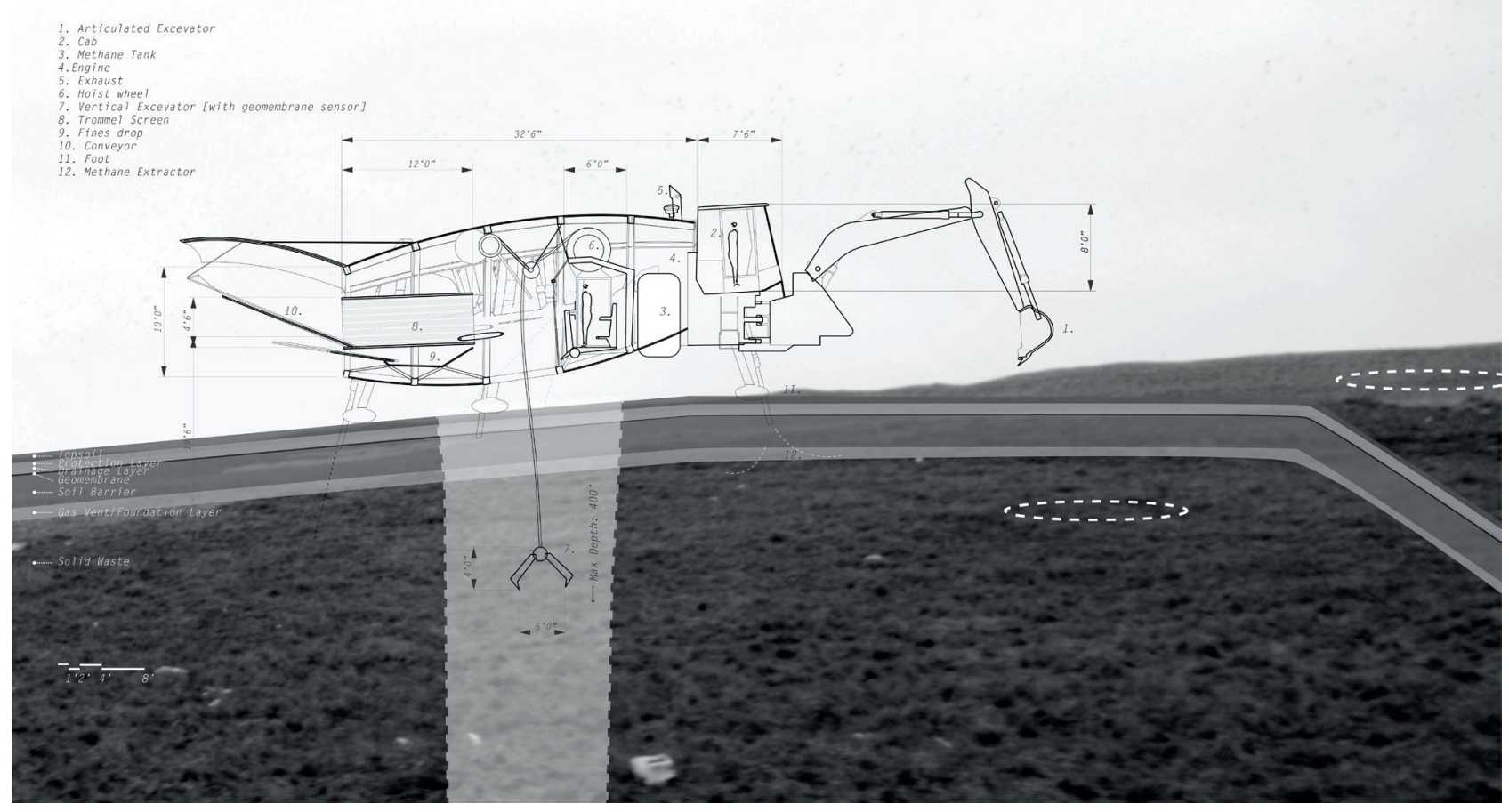

FIGURE 8: DRTE (Directed Robotic Trash Extractor).

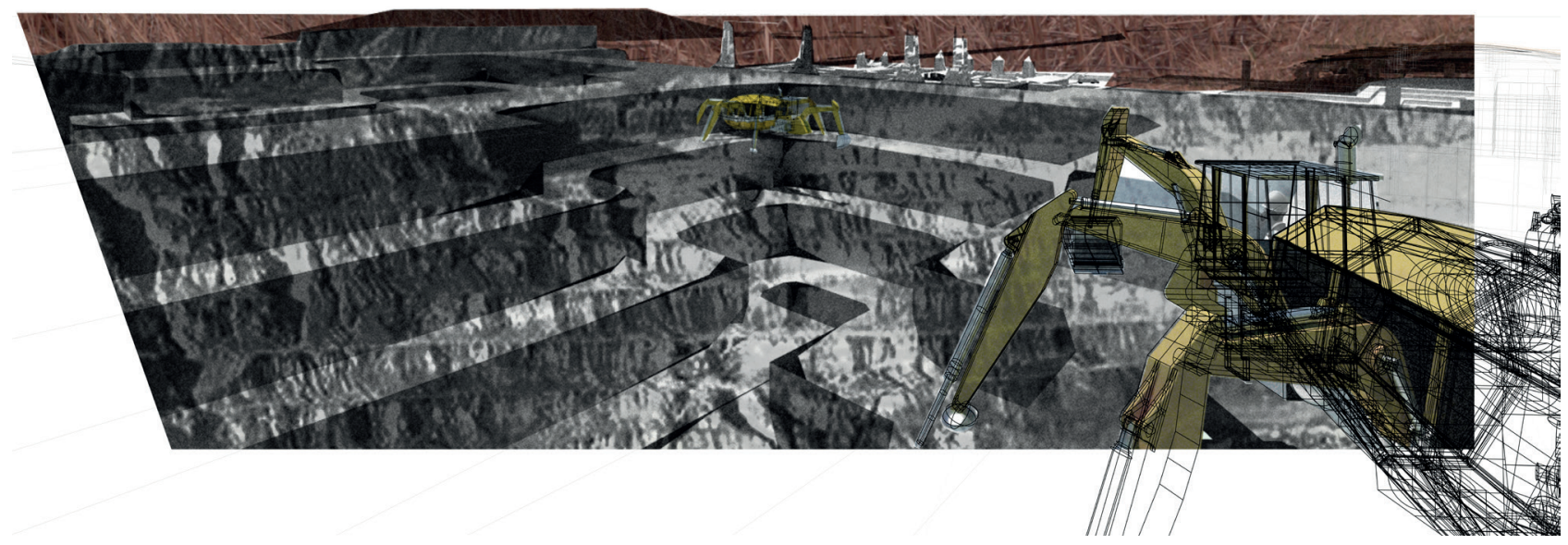

FIGURE 9: DRTE on the mound. 
into the backlot. The Head-houses also serve as central locations for public interaction through an interpretive center featuring dynamic viewing experiences of the facility. Here, a convection chimney functions to suck smelly air from the recently exhumed material, generating electricity from a turbine when conditions allow, and moreover serves as a dramatic backdrop to the moment of revelation witnessed below (Figures 11, 12).

Workers stationed in the pit watch for materials specific to their operations, radioing back to their colleagues stationed along the line. The public is welcome at any time to view or participate in the experience. The structure predicts its own obsolescence, and therefore is designed for disassembly.

\subsection{The line}

Along the $250 \mathrm{~m}$ (800 ft) long conveyor-belt lines, lots are rented at rates based on proximity. Closer to the headhouse, the higher the rent. Although nothing would prevent a single company from removal of all material on the belt, a significant cross section of material exists on each conveyor belt to warrant multiple interests served. Cree pulls aluminum and zinc for recycling into their LED heat-sinks, while the Glad company contracts workers and robotic armatures to capture spent plastic bag material; computer repair specialists collect E-waste, or an artist collective rents space as a testing ground for multi-media work. While typical sorting facilities of today will only sort what is economically productive to their networks, the line allows

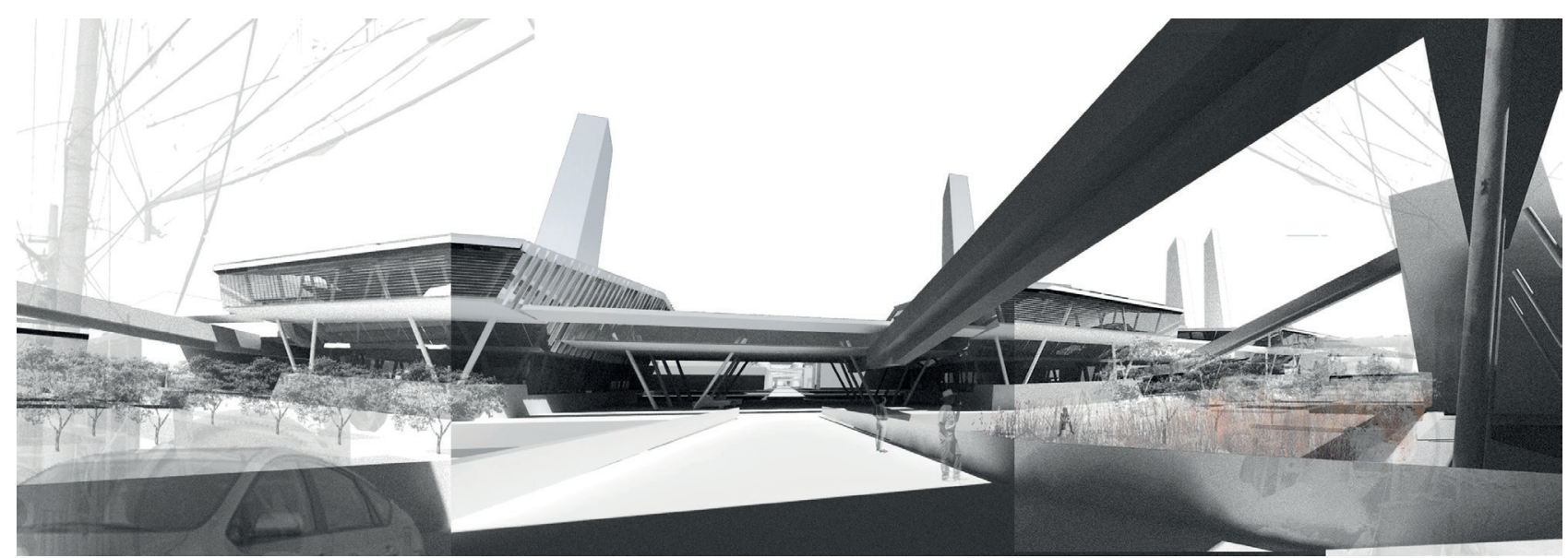

FIGURE 10: Power-remediation.

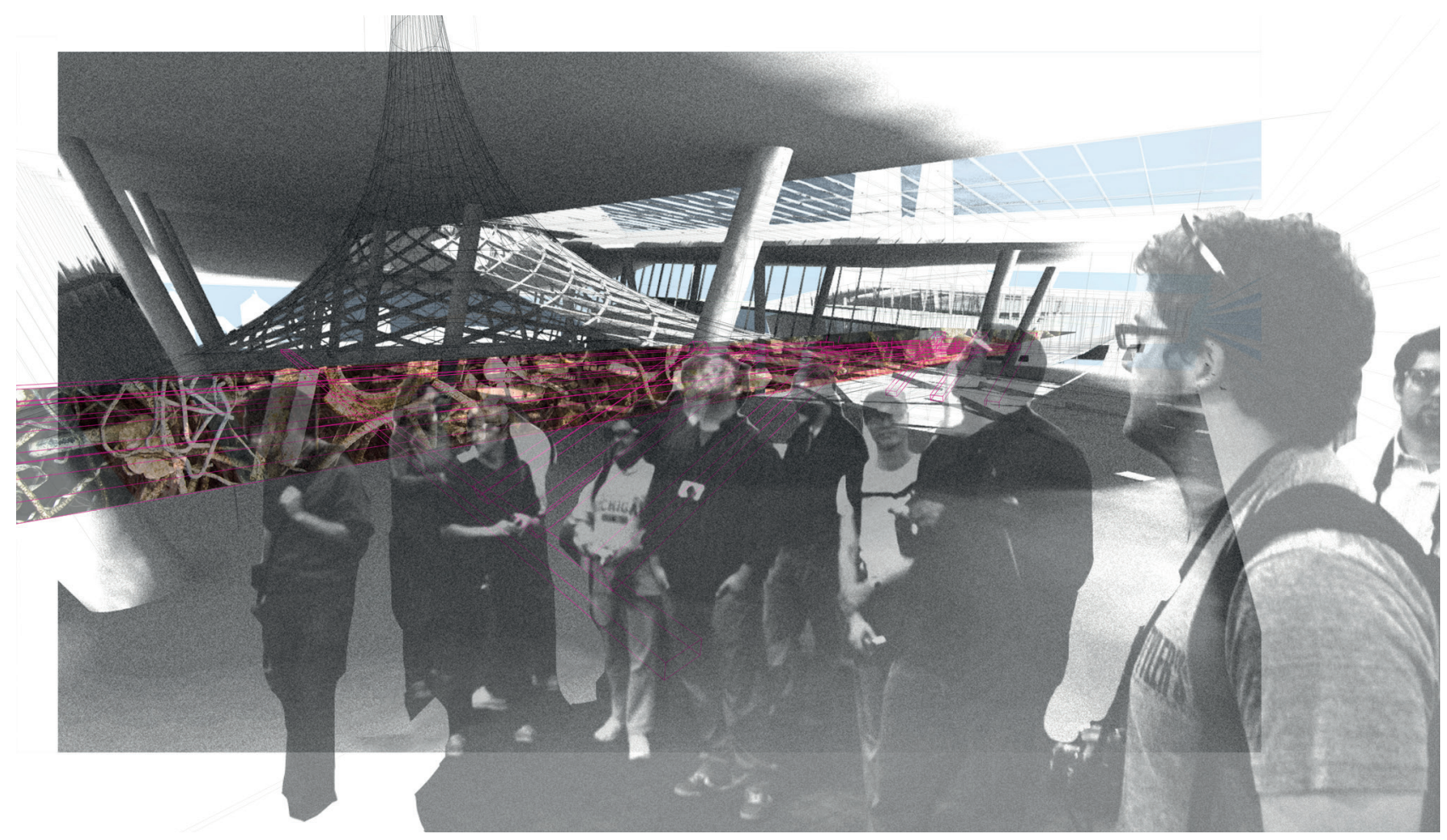

FIGURE 11: The headhouse. 
any material to be productive again: rusty rebar, Styrofoam cups, or electric scissors (Figure 13).

\subsection{The Backlot (Industrial market)}

The backlot's zoning accommodates any configuration of structure within each $550 \mathrm{~m}^{2}\left(6000 \mathrm{ft}^{2}\right)$ lot - tenants may build any structure they wish within general guidelines to facilitate their own agenda, subdividing or accumulating additional lots as needed. As tenants move in, cross-pollination occurs. Independent harvesters may begin working together, creating new material networks and economies unavailable to traditional recycling practices (Figure 14).

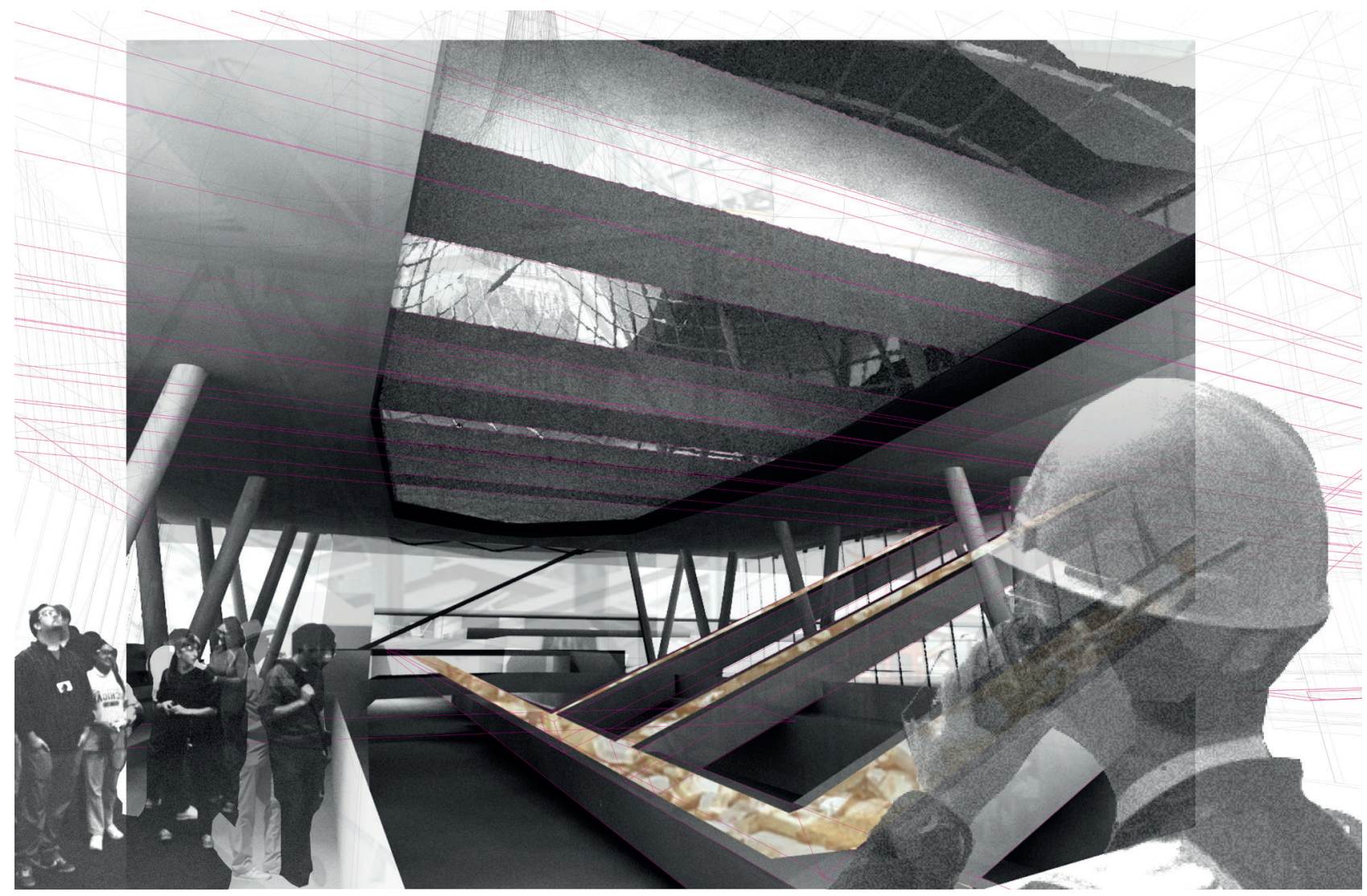

FIGURE 12: The pit.

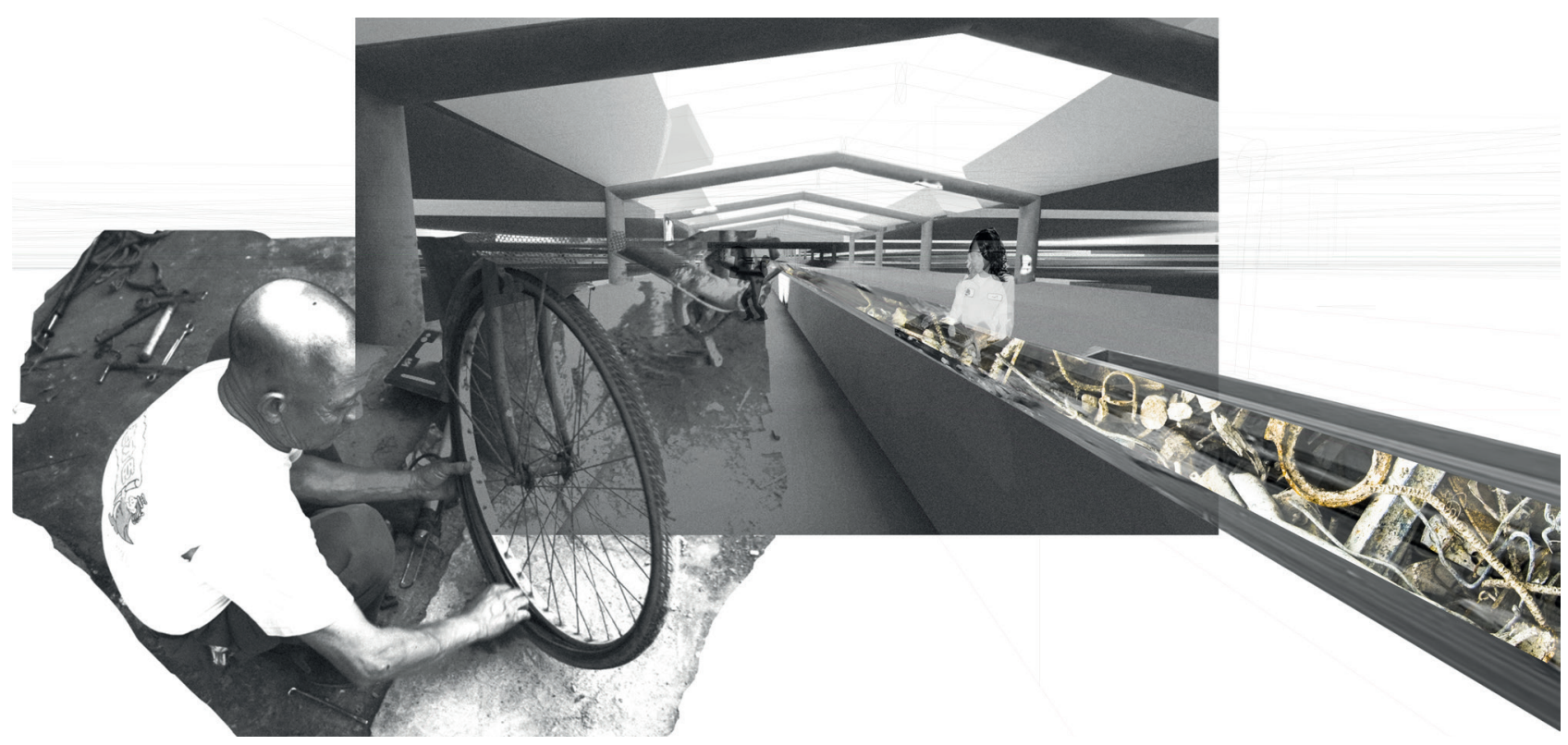

FIGURE 13: The line. 


\subsection{Export}

Unclaimed material is either injected into the global supply lines to buyers via train or truck, or if the economy does not exist for particular materials, those materials may be re-deposited in the landfill for future extraction (Figure 15).

\subsection{Dirt Farm}

As a significant portion of the landfill consists of soil (generally used as daily cover), any reclaimed dirt may be remediated and sold to customers (Figure 16).

\section{CONVEYOR-BELT INFRASTRUCTURE}

The junkyard lacks apparent form - an underlying logic exists, but it does not present itself formally to the visitor, making accessibility of materials difficult. Conversely, the traditional recycling facility is logistics based but one-dimensional, seeking specific materials for specific destinations. The Sorted Project proposes that a third, hybrid solution may be the mechanism needed at this newly opened node in material flows.

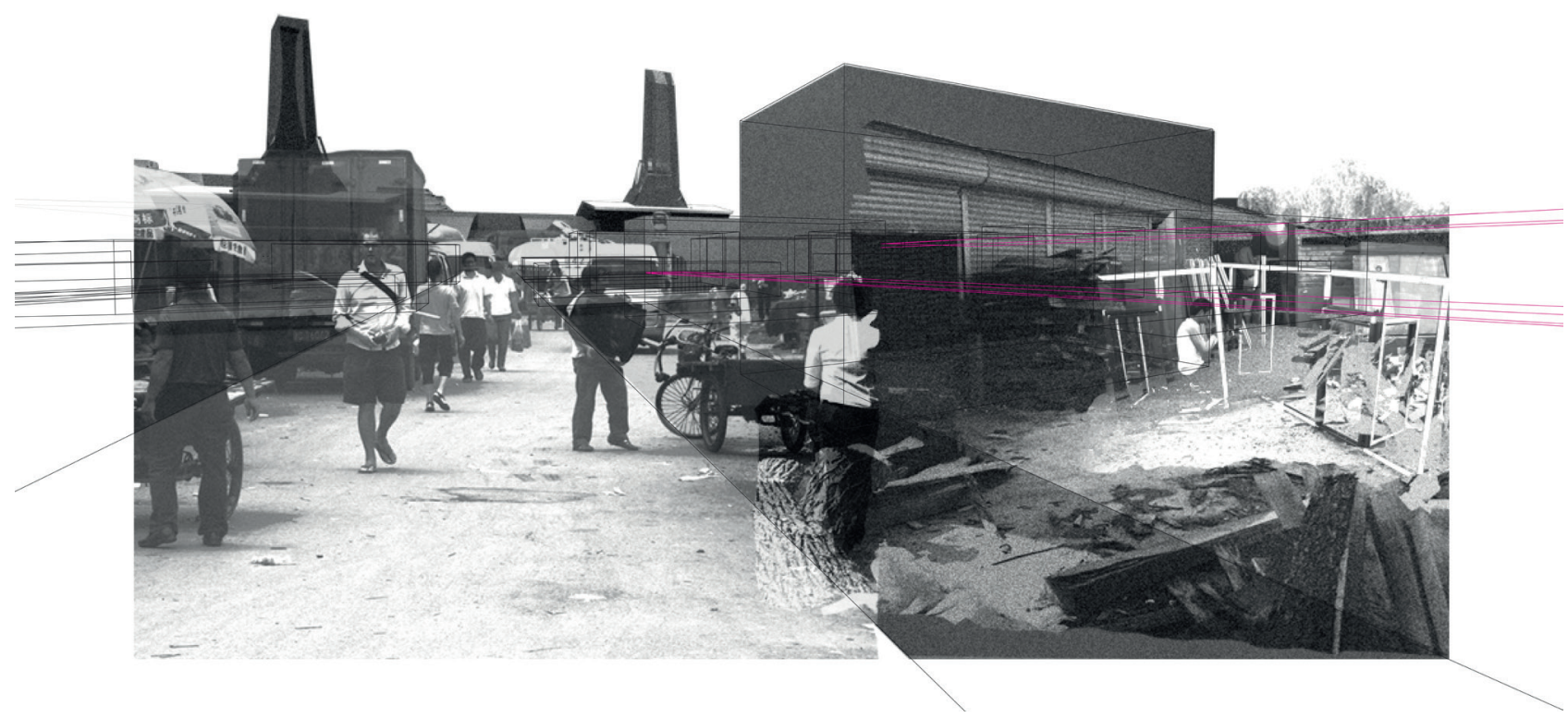

FIGURE 14: Backlot.

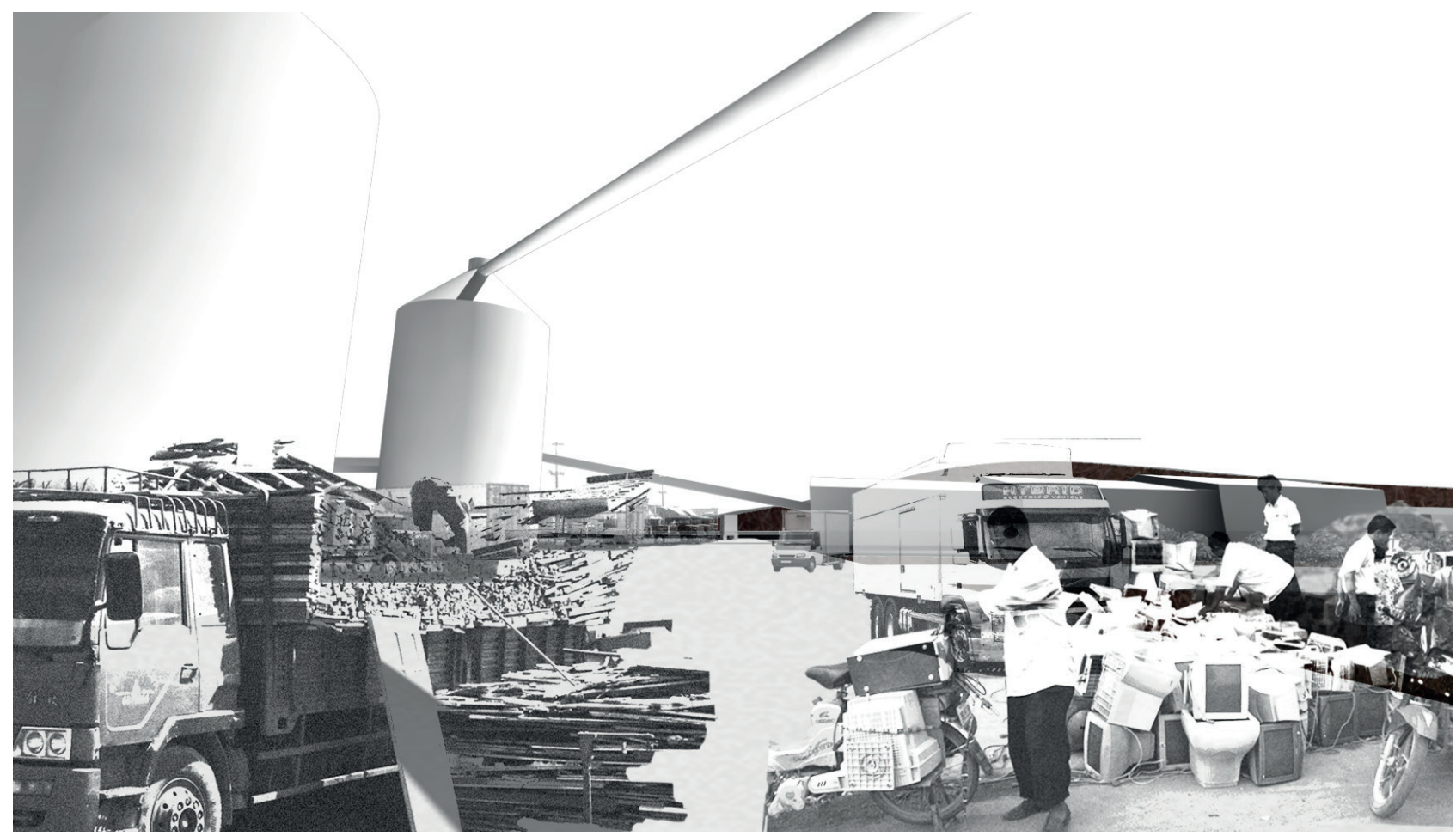

FIGURE 15: Export. 


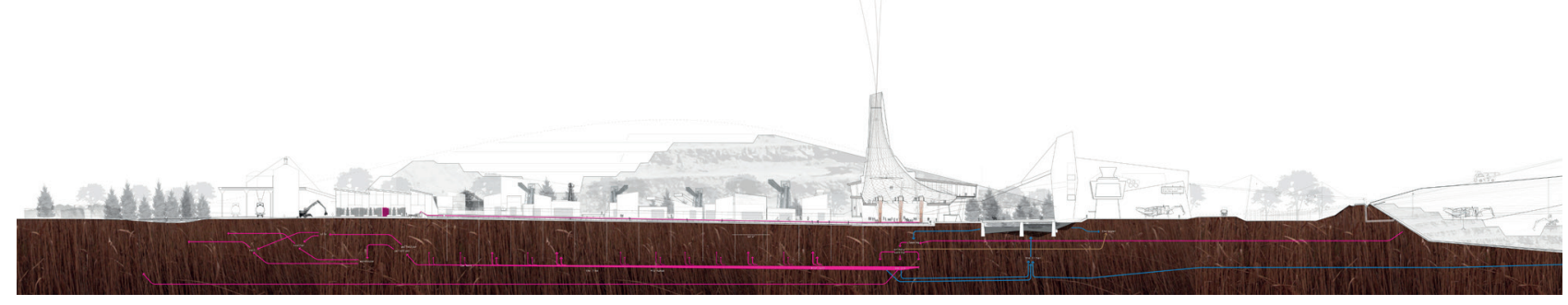

FIGURE 16: Site section.

An emergent market-based urbanism of reuse suggests that on-the-ground access to the flow is critical in fostering novel material industries. Adjacency could allow for disparate tenants to expand their networks in wholly unique and emergent ways, a phenomenon untenable in the Drosscape. As previously unproductive material finds meaning and purpose, a new economy emerges (Figure 17).

Beyond the scale of the site, the project suggests that re-territorialization of the regional urban ecology is imminent as new industrial, commercial, and agricultural spheres grow in the landfill's shadow, taking advantage of new opportunities. This intensification could adversely affect local residents of the area, as low-density residential development is not a productive adjacency. Rezoning (or un-zoning) of landfill adjacencies will be inevitable to facilitate this industrial ecology.

Projecting beyond the site of the landfill, Landfill Urbanism suggests potentials for pre-cycling. Instead of merely digging up the past, the urban and emergent sorting techniques presented could provide the needed filter to redirect material flows before the landfill. Sites and potentials for future work could include denser urban contexts, commercial/light industrial districts, transfer stations, and transportation hubs (Figure 18).

Although technological advancement will no doubt minimize the impacts of increased environmental degradation, alternatives (or augmentations) to existing social practices are critical to maintaining our way of life. Landfill Urbanism operates within today's reality that global capital drives contemporary urbanization, and is not seen as a long-term solution, nor does it seek to fix past wrongs. In a perfect world, we as a species would realize that completing the cycle is not a matter of choice, but a critical element of sustaining our very existence. In the meantime, and under the constraints of our current socio-economic reality, the project seeks to take advantage of every possible material and economic opportunity, and therefore is unforgiving in its operations. Yet it projects hope that through a reconditioning of our relationship to waste, the project's very existence will cease to be relevant at some sought-after moment in the future (Figure 19).

The problem of waste is deep - it's systemic. Landfill Urbanism realizes human nature for what it is; Blane Brownell notes that "Homo Sapiens is the only species that creates what may be truly considered waste." But the cat is out of the bag so to speak, regarding the convenience of that light-weight throw-away cat-caring plastic bag. We must, as a species realize that completing the cycle is not a matter of choice, a granola-crunching utopian manifestation, but a critical element of sustaining our very existence and civilization. Landfill Urbanism is not the long-term solution, nor does it seek to fix past wrongs. It is wholly opportunistic in operating in our current reality, and therefore it is parasitic in its deployment and unforgiving in its operations. Yet it projects hope that its very existence will cease to be relevant at some sought-after moment in the future. On the landscape of the landfill, entrepreneurs, corporations, artists and consumers are pitted against each other in the epic battle for control of energetic flow, where closing the cycle on material and energy flow is the key to power.

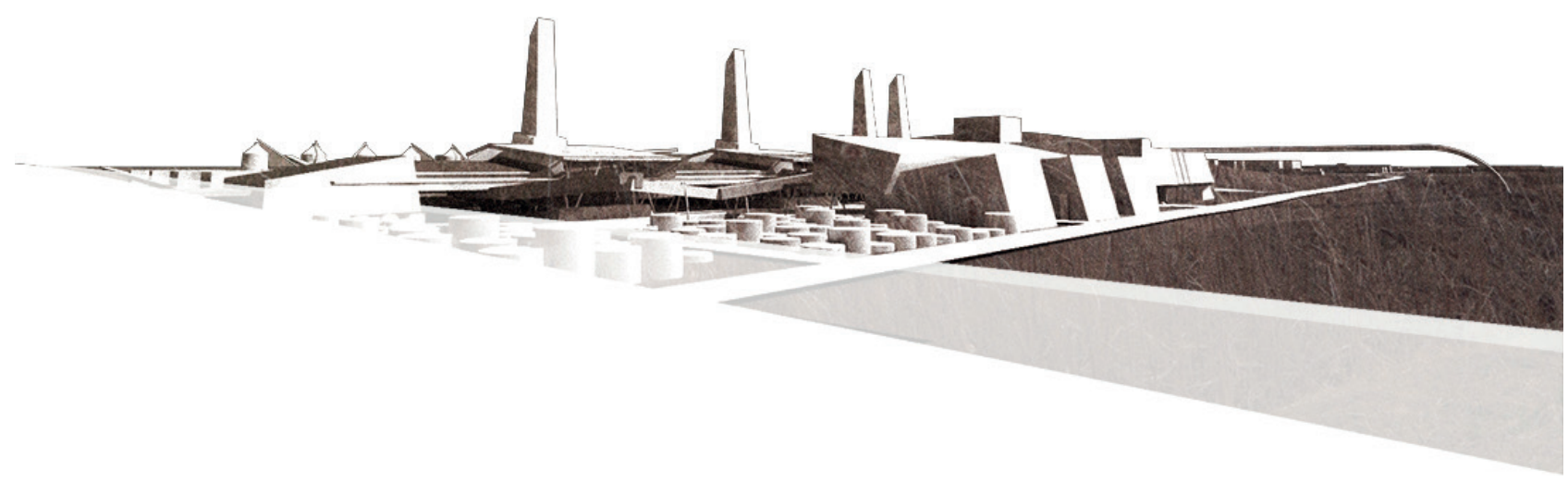

FIGURE 17: Freeway - 1275North. 




FIGURE 18: Phasing (continues in the next page). 


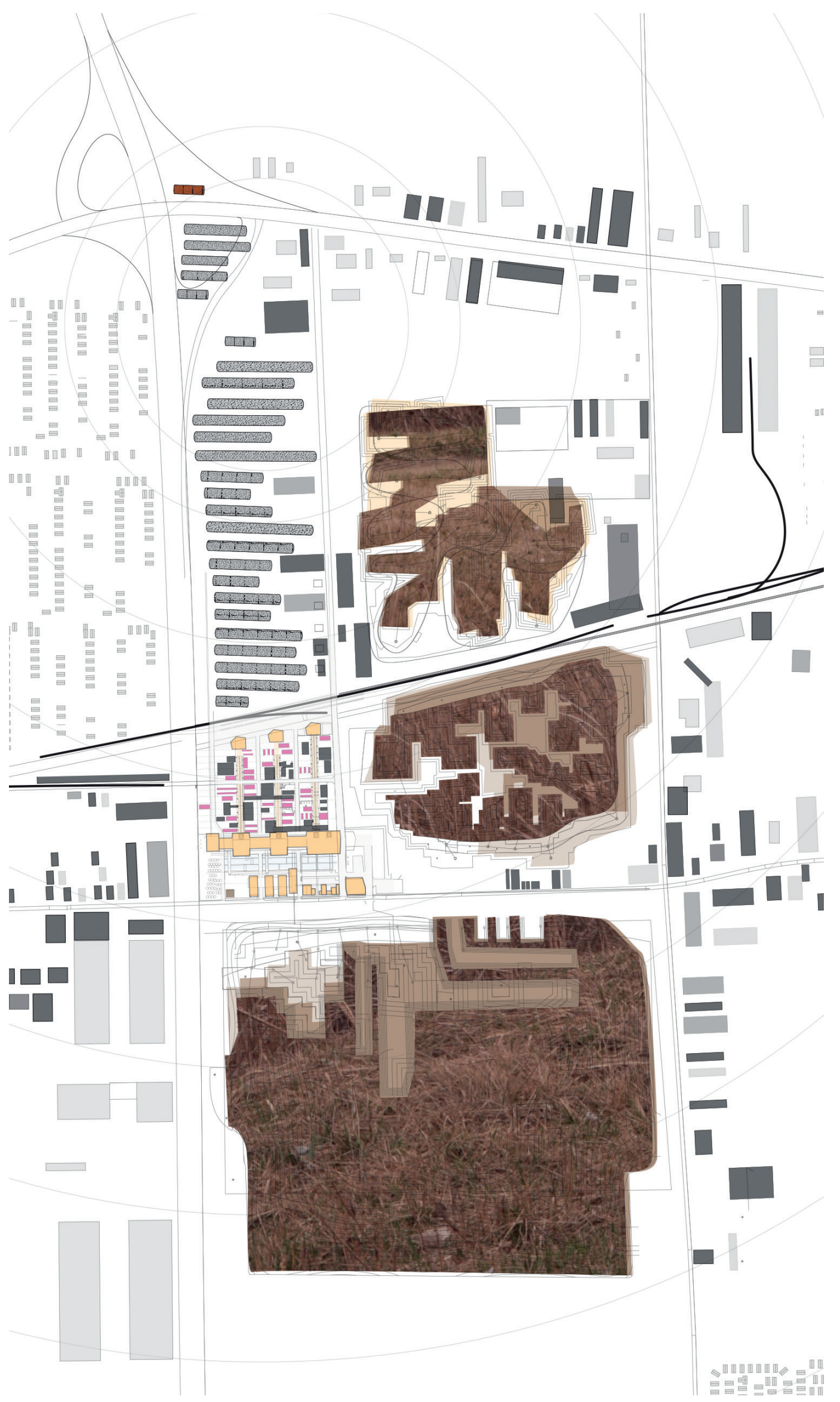

(continues from the previous page) 


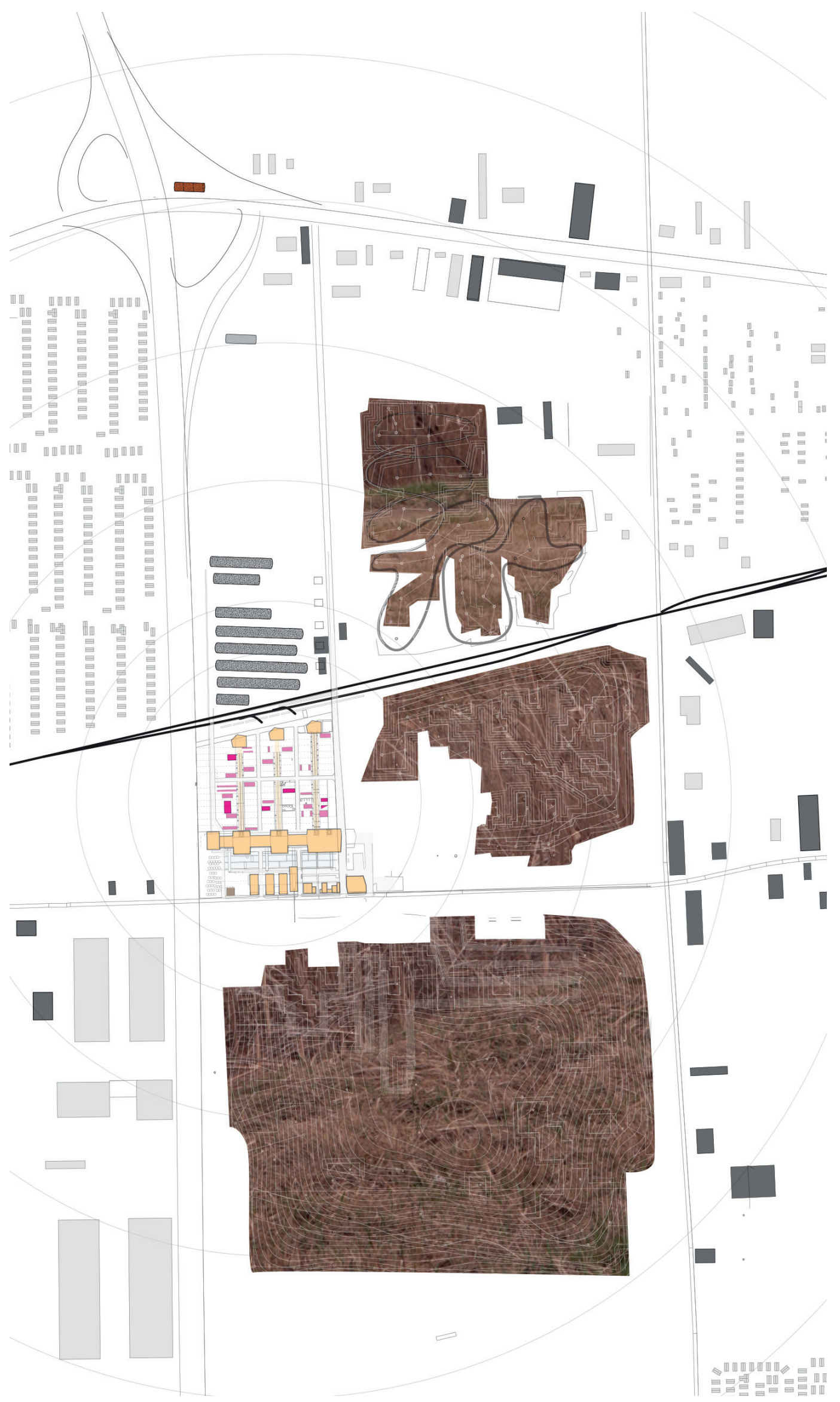

(continues from the previous page) 




FIGURE 19: General view of the proposed project.

\section{ACKNOWLEDGEMENTS}

Thanks to my Thesis Advisor, Geoff Thün, at Taubman College of Architecture at University of Michigan over the academic year 2009-2010, who coached me in the ways of urbanisms, landscapes, large scale systems and all the rest. Also to my colleagues who were influential at the time, and the Thunder Thesis Group.

\section{REFERENCES}

Belanger, P., 2009. Landscape as Infrastructure. In Landscape Journal, University of Wisconsin Press

Berger, A., 2006. Drosscape: Wasting Land in urban America. Princeton Architectural Press, New York, NY, p. 186

Berger, A., Waldheim, C., 2008. Logistics landscapes. In Landscape Journal, University of Wisconsin Press

Brownell, B., 2010. Material Ecologies in Architecture. Design Ecologies. Ed. Lisa Tidler \& Beth Blostein, Princeton Architectural Press, New York NY, p. 229

Environmental Protection Agency Municipal Solid Waste Generation, Recycling, and Disposal in the United States: Facts and Figures, 2007

Ghosn, R., 2010. New Geographies 2: Landscapes of Energy. Harvard University Press, Cambridge NA

Hecht, N.L., 1983. Design principles in resource recovery engineering, Butterworths
Hiester, T.R, Shafer, H.J, Feder, K.L., 2009. Field Methods in Archaeology 7th Ed. Left Coast Press

Joachim, M., 2008. Rapid re(f)use: Waste to resource city 2120 . Terreform 1. www.terreform.org

Michigan Department of Environmental Quality. Report of solid waste landfilled in Michigan: October 1, 2008 - September 30, 2009. Sygo, J., et al. Lansing, Michigan, January 15, 2010

Michigan Department of Environmental Quality Renewable Operating Permit Staff Report N6009 (Sauk Trails Landfill). January 5, 2007

National Center for Resource Recovery. Sanitary Landfill, A State-ofthe-Art Study. Lexington Books, 1974

Murphy, C. \& Rathje, W., 2001. Rubbish! The archaeology of garbage. The University of Arizona Press

Pichtel, J., 2005. Waste Management Practices: Municipal, Hazardous, and Industrial. CRC Press, Boca Raton, FL

Prechthai, T., et al., 2008. Quality assessment of mined MSW from an open dumpsite for recycling potential. Asian Institute of Technology, Klong Luang Pathumthani Thailand, 2 November, 2008

Rogers, H., 2005. Gone Tomorrow: The Hidden Life of Garbage. The New Press, New York, NY

Rosenthal, E., 2009. Smuggling Europe's Waste to Poorer Countries. The New York Times, 26 September 2009

Qian, X., Koerner, R.M., Gray, D.H., 2002. Geotechnical Aspects of Landfill Design and Construction. Prentice Hall, New Jersey

Waste without borders in the EU?: Transboundary shipments of waste. European Environment Agency. Copenhagen DK, 2009

Woodland Meadows Landfill. Waste Management Inc, 2009. www. wm.com 